\title{
A Mixed Methods Evaluation of an Inclusive Sexual History Taking and HIV Prevention Curriculum for Trainees
}

\author{
Katherine Frasca, $M D^{7}$, Jose Castillo-Mancilla, $M D^{7}$, Monica C. McNulty, $M S^{2}$, \\ Susan Connors, $P h D^{3}$, Elizabeth Sweitzer, $M A^{3}$, Shanta Zimmer, $M D^{1,2}$, and \\ Nancy Madinger, $\mathrm{MD}^{7}$
}

${ }^{1}$ Division of Infectious Diseases, University of Colorado, Aurora, CO, USA; ${ }^{2}$ School of Medicine, University of Colorado, Aurora, CO, USA; ${ }^{3}$ School of Education and Human Development, University of Colorado Denver, Aurora, CO, USA.

BACKGROUND: Health disparities exist in HIV risk in the USA among the lesbian-gay-bisexual-transgender-queer (LGBTQ) community. There is also scarce literature on curricula for HIV prevention and pre-exposure prophylaxis (PrEP) for trainees.

AIM: To create a curriculum to train residents to perform inclusive sexual history taking and HIV prevention care. The curriculum covers sexual history, LGBTQ health, sexually transmitted infections, and HIV risk assessment and risk reduction counseling including use of PrEP.

SETTING: A dedicated PrEP Clinic was created within an Academic Medical Center Outpatient HIV Clinic. Patients were primarily LGBTQ identified, but also included HIV sero-discordant couples, cisgender individuals, heterosexual invididuals, and those with experience of homelessness, sex work, and substance abuse.

PARTICIPANTS: Thirty-four internal medicine residents completed the course between November 2017 and May 2018.

PROGRAM DESCRIPTION: The curriculum was delivered as Just in Time Teaching (JiTT) via online virtual patient cases followed by directly observed clinical care at a large urban PrEP clinic.

PROGRAM EVALUATION AND RESULTS: The effectiveness of the curriculum was assessed through paired pre/post-self-assessment surveys $(n=19)$, additional post-surveys on the online modules $(n=22)$, and interviews $(n=9)$. Many respondents reported no prior training or inadequate prior training in the course content. As a result of the course, participants reported statistically significant increased confidence and comfort in all seven HIV prevention topic areas, with the greatest gains in safe sex counseling for LGBTQ patients and in discussing PrEP (mean changes of 1.21, 1.58 on 5-point Likert scale, respectively, $p<0.0001$ ). Six of nine interviewees post-course had applied what they learned to patient care; five indicated their learning would benefit patients.

DISCUSSION: An HIV prevention curriculum focused on cultural humility in care can improve trainee's skills in

Electronic supplementary material The online version of this article (https://doi.org/10.1007/s11606-019-04958-z) contains supplementary material, which is available to authorized users.

Received June 11, 2018

Revised November 30, 2018

Accepted February 22, 2019

Published online April 29, 2019
HIV risk reduction counseling, including PrEP, among all patients including those identifying as LGBTQ.

KEY WORDS: medical education curriculum development/evaluation; disparities; HIV; underserved populations; preventative care.

J Gen Intern Med 34(7):1279-88

DOI: $10.1007 /$ s11606-019-04958-Z

(C) Society of General Internal Medicine 2019

\section{INTRODUCTION}

Pre-exposure prophylaxis (PrEP) is a highly effective method to prevent HIV acquisition but is currently underutilized in the USA. ${ }^{1,2}$ Tenofovir disoproxil fumarate-emtricitabine for use as PrEP was FDA approved in 2012, with Centers for Disease Control (CDC) guidelines published in 2014. ${ }^{3}$ Multiple randomized controlled trails on PrEP use among men who have sex with men (MSM) and heterosexual sero-discordant couples have shown efficacy of over $90 \%$ in adherent participants. ${ }^{4-7}$ With over 40,000 new HIV infections per year in the USA, and over 70\% among MSM, PrEP is a key strategy to end the HIV epidemic. ${ }^{8}$ While MSM, including gay and bisexual men, are at greatest risk of HIV in the USA, transgender and cisgender individuals, particularly women of color, are also at risk. ${ }^{3}$

There are additional health disparities in HIV risk beyond the LGBTQ community. By current estimates, one in two African American MSM, one in four Latino MSM, and one in 11 Caucasian MSM in the USA will acquire HIV in their lifetimes. ${ }^{9}$ Transgender women have an estimated $21 \%$ HIV prevalence, with the highest rates among minority racial groups. ${ }^{10}$ Health disparities also exist for PrEP use, with recent utilization data showing the majority are self-identified white/ Caucasian; only $1 \%$ of the estimated 500,000 African Americans and only $3 \%$ of the estimated 300,000 Latinos who are eligible have received PrEP. ${ }^{2}$

Therefore, there is a need to focus on HIV prevention, including offering PrEP, to reduce health disparities in HIV risk among LGBTQ, African Americans, and Latinos. Identification of PrEP candidates through comprehensive sexual history taking inclusive of gender and sexual minority populations by primary care providers (PCPs) is key. ${ }^{11,12}$ However, 
studies have shown slow uptake of PrEP use among PCPs, ${ }^{12}$, 13 primarily due to lack of knowledge and experience in PrEP. ${ }^{14-16}$ Other barriers include lack of experience in HIV and sexually transmitted infection (STI) risk assessment. ${ }^{17,}{ }^{18}$ Higher knowledge scores regardless of specialty are associated with increased willingness to offer PrEP. ${ }^{19}$, ${ }^{20}$ There is a paucity of literature on curricula on PrEP and HIV prevention for trainees. ${ }^{21,22}$ Primary barriers for trainees in PrEP were lack of training and knowledge, ${ }^{23}$, ${ }^{24}$ as well as heterosexism. ${ }^{25}$ Exposure to LGBTQ and patients at risk of HIV led to increased PrEP awareness, ${ }^{23}$ suggesting that PrEP education for trainees with exposure to these at-risk patient populations is warranted.

The foundation of both HIV risk assessment and LGBTQ health is a thorough sexual history inclusive of gender and sexual minority populations, to adequately assess candidacy for HIV prevention tools including PrEP. A systemic review of sexual health in medical education has described current training as "inadequate, variable, non-standard." ${ }^{26}$ Methods suggested to improve sexual history taking have found active learning, such as practice with patients, to be most effective, ${ }^{27-29}$ improving trainees' comfort. ${ }^{30-33}$ In addition, trainees report lack of comfort, knowledge, and experience in managing LGBTQ patients, ${ }^{34-36}$ particularly transgender individuals. ${ }^{37-39}$ On average, medical schools provide only $2 \mathrm{~h}$ (IQR $0-4 \mathrm{~h}$ ) of training on LGBTQ health. ${ }^{40}$

To address the above-mentioned gaps, we developed a formal PrEP and HIV prevention curriculum grounded in thorough sexual history taking with incorporation of LGBTQ terminology to identify patients at risk of HIV in a culturally humble manner.

\section{AIM}

The goal of the HIV prevention curriculum was for residents to acquire the knowledge, skills, and attitudes necessary to perform an inclusive, culturally humble sexual history and to evaluate and counsel patients at risk of STIs and HIV, including the provision of pre-exposure prophylaxis (PrEP), for prevention of HIV. The following objectives were intended to be achieved by the end of the rotation:

Objective 1: to recognize their own attitudes about gender identity, sexual orientation, and sexual practices, including identifying language that implies bias

Objective 2: to identify the barriers to care and the unique health risks of LGBTQ patients to develop appropriate treatment plans with these patients to address inequalities

Objective 3: within a patient interview, to:

Apply and demonstrate culturally appropriate communication skills in sexual history taking

Perform an appropriate screening physical exam and laboratory testing for sexually transmitted infections and HIV as per $\mathrm{CDC}$ guidelines
Demonstrate effective behavioral counseling and ability to utilize PrEP for the prevention of HIV in at-risk populations

\section{SETTING AND PARTICIPANTS}

The learners were Internal Medicine and Medicine-Pediatrics residents PGY levels 1-4; the majority were mid- to end-ofyear PGY-1. The majority attended as part of a standard Infectious Diseases inpatient rotation, a minority from an outpatient rotation, from November 2017 to May 2018. The rotation occurred at the UCH Infectious Diseases Clinic dedicated PrEP Clinic, one half day per week. This PrEP Clinic serves a primarily LGBTQ population with a substantial portion of self-identified Latinos/African Americans referred from a community-based organization. The population also includes heterosexuals, cisgender individuals, HIV serodiscordant couples, and those with experience of homelessness, sex work, and substance abuse. Most residents attended two 4-h sessions; a minority attended one session. The sessions began with a self-assessment pre-survey followed by online modules of patient cases. Next, a clinician trained in PrEP observed the residents performing sexual history taking, HIV risk assessment, and risk reduction counseling with patients. Faculty provided formative feedback, and residents completed a post-survey at the end of the last clinic session.

\section{PROGRAM DESCRIPTION}

The HIV prevention curriculum is an innovative model created by the study team using Just in Time Teaching (JiTT),${ }^{41}$ to integrate content delivery via online, case-based modules followed by direct clinical practice in a PrEP clinic. The content was reviewed by all members of the study team, which contains several experts in medical education, LGBTQ health, and HIV prevention. The online curriculum is composed of six clinical cases with two objectives per case; each case addresses one of the following core topics: (1) LGBTQ terminology; (2) inclusive, sexual history taking; (3) LGBTQ and HIV-related health disparities; (4) STIs; (5) HIV risk assessment and prevention counseling including harm reduction; and (6) PrEP candidacy and care delivery (see online Appendix D). The curriculum is delivered on SparkWorks, which allows for integration of multiple choice questions into clinical cases. Core content utilized the CDC guidelines on PrEP and STIs, ${ }^{3}$, ${ }^{42}$ CDC's "A Guide to Taking A Sexual History," 43 the PLISSIT model, ${ }^{44}$ and the National HIV Prevention Training Center's "STD/HIV Risk Reduction Counseling". ${ }^{45}$ Content on LGBTQ health was obtained from the National LGBT Health Education Center and the Gay and Lesbian Medical Association's guides. ${ }^{46-48}$ A full literature search on these topics was conducted twice, once by the study team and once by a health sciences library staff member. 


\section{PROGRAM EVALUATION}

\section{Methods}

Our survey was conducted as a paired pre-post-analysis to evaluate the effect of the curriculum on comfort and training levels around sexual history taking and safe sex counseling including HIV prevention and PrEP, specifically addressing LGBTQ patients. The paired pre-post-survey of selfassessment questions on a 5-point Likert scale (see online Appendix A) was modeled after a survey created at Maine Medical Center. ${ }^{49}$ To assess the goals of our curriculum, the study team created additional questions, addressing the ability to provide HIV prevention counseling and to initiate a discussion about PrEP. In addition, questions were added to the postsurvey to address the online curriculum (see online Appendix B). Results from the pre-post-paired surveys and non-paired post-survey content were integrated into qualitative data from semi-structured interviews by the qualitative research team as a specific study design. The study was approved as exempt by the Colorado Multiple IRB (17-2051). Participants received emails generated from the REDCap database and the Evaluation Center regarding their voluntary, confidential participation in the study through completion of the survey and/or interviews. They filled out surveys in a secure REDCap database and no respondent identifiers were included in the data file. Instead, unique identifiers were generated within REDCap which were later used to pair pre- and post-survey responses.

\section{Quantitative Methods}

Paired pre-post-surveys were conducted as described above and analyzed using SAS. Change in comfort level regarding sexual history taking, discussion of safe sexual practices, preexposure prophylaxis, and counseling on reduction of STIs/ HIV were assessed with a pre/post-paired analysis of the Likert scale responses using the Wilcoxon signed rank statistic. Spearman correlation coefficients were used to assess the extent of correlation between comfort levels with various aspects of patient care related to sexual health at the presurvey time point. Fisher's exact test was used to determine change in amount of training-received aspects of patient sexual health care between the pre- and post-survey time points. McNemar's test was used to assess change in preferred training format between the pre- and post-survey time points.

\section{Qualitative Methods}

The Evaluation Center, School of Education and Human Development, University of Colorado Denver, conducted semistructured interviews with residents completing the curriculum. Evaluators prepared the interview protocol (see online Appendix C) in collaboration with the study team using the Kirkpatrick model of evaluation of professional development as a framework. ${ }^{50,51}$ Using this framework, at level 1, evaluators asked how engaging and relevant participants found the training. At level 2, evaluators investigated the degree participants acquired new knowledge, skills, attitudes, confidence, and commitment because of the training. At level 3, they asked how new learning is applied and examined. Finally, at level 4, evaluators probed to learn if participants believe their new learning is helping them to achieve or if they are on track to achieve the intended outcomes (e.g., improved health for patients). Evaluators also collected formative feedback on the curriculum and integrated all qualitative findings with the quantitative results.

Evaluators recruited interviewees by email from the list of residents completing the course between November 2017 and May 2018. In April-May 2018, evaluators conducted the interviews by phone with residents who voluntarily agreed to participate; interviews were digitally recorded and transcribed. No personal identifiers were used in the transcribed data. Transcripts were coded using NVivo 11 (QRS International) qualitative software; the interview protocol served as the initial codebook, and additional codes were identified as themes emerged. Representative quotes were selected to illustrate key themes. To provide further insights on the impact of the course, evaluators also integrated results of the paired pre-post-surveys (see online Appendix A).

\section{INTEGRATED RESULTS}

\section{Prior Training}

To understand the impact of the HIV Prevention curriculum, it was important to account for any prior training in the content before residents completed the course.

\section{Interview Results}

Nine (26.5\%) interviewees agreed to participate; eight of the nine reported no prior training in pre-exposure prophylaxis (PrEP). In the other course content areas, training experiences varied; however, many expressed that prior training was "very introductory ... very basic" and did not lead to competence. Five of nine reported no training in taking a sexual history or in LGBT health. Four reported no training in discussing the prevention of STIs. Only one resident reported considerable prior training in the course content areas.

\section{Survey Results}

The pre-survey response rate was $26 / 34$ or $76.5 \%$ and the postsurvey response rate was $22 / 34$ or $64.7 \%$; there were 19 (55.8\%) matched pre-post-surveys. Survey results on prior training were consistent with interview data (Table 1). While most respondents $(n=19)$ reported receiving some prior training in the course topic areas, few reported they had extensive training leading to competence. Over half (58\%) reported they had no prior training in providing PrEP (Fig. 1). 
Table 1 Results of Pre-Post-Self-Assessment Survey: Training

\begin{tabular}{|c|c|c|c|c|c|c|c|}
\hline \multirow{2}{*}{$\begin{array}{l}\text { Question: "How much } \\
\text { training have you } \\
\text { received..." }\end{array}$} & \multicolumn{3}{|c|}{ Pre $(n=19)$} & \multicolumn{3}{|c|}{ Post $(n=19)$} & \multirow{2}{*}{$\begin{array}{l}P \text { value } \\
\text { (Fisher's } \\
\text { exact test) }\end{array}$} \\
\hline & $\begin{array}{l}\text { Extensive } \\
(\%)\end{array}$ & $\begin{array}{l}\text { Some training/ } \\
\text { some but inadequate } \\
(\%)\end{array}$ & $\begin{array}{l}\text { None } \\
(\%)\end{array}$ & $\begin{array}{l}\text { Extensive } \\
(\%)\end{array}$ & $\begin{array}{l}\text { Some training/ } \\
\text { some but inadequate } \\
(\%)\end{array}$ & $\begin{array}{l}\text { None } \\
(\%)\end{array}$ & \\
\hline $\begin{array}{l}\text { 9. ...for learning how to take } \\
\text { a patient's sexual history? }\end{array}$ & 15.79 & 84.21 & 0 & 42.11 & 57.89 & 0 & 1.00 \\
\hline $\begin{array}{l}10 \text {...for learning how to take } \\
\text { a LGBTQ patient's sexual } \\
\text { history? }\end{array}$ & 0 & 83.33 & 16.67 & 38.89 & 55.56 & 5.56 & 0.21 \\
\hline $\begin{array}{l}\text { 11. ...on providing } \\
\text { pre-exposure } \\
\text { prophylaxis }(\mathrm{PrEP}) ?\end{array}$ & 0 & 42.11 & 57.89 & 21.05 & 73.68 & 5.26 & 1.00 \\
\hline $\begin{array}{l}12 . . . \text { on providing counseling } \\
\text { on methods to reduce STIs, } \\
\text { including HIV, to your } \\
\text { patients? }\end{array}$ & 10.53 & 84.21 & 5.26 & 36.84 & 63.16 & 0 & 0.12 \\
\hline
\end{tabular}

\section{Level 1: Participant Reactions}

\section{Online Experience}

Eight of nine residents reported the online portion of the course was relevant and engaging. Residents described how the online module contributed to their learning:

"One of the primary parts that was really, really helpful was going into the indications for PrEP ... because it helps you [ask] those questions when you think someone might be a good candidate. ... I felt like the dialogue portion of the modules was really well done. .... It gave me a little bit of a script, which was very helpful."

"It was actually really, really good. I really did learn quite a bit more ... in terms of ... how we should approach persons who are transgender, especially with regard to pronoun use and simply walking into a room and not saying, 'Hi Mr. or Mrs. so and so,' just to say, 'Hi Denise. Is that how you preferred to be called or addressed?' That was a good example."

Five residents noted the content of the online portion of the course was not completely new to them; rather, it provided more depth than previous training experiences. However, four interviewees reported encountering entirely new content. One interviewee explained:

"Honestly, the entire concept of PrEP ... learning about it was essentially new to me. I was familiar with the concept of post-exposure prophylaxis, but not preexposure prophylaxis."

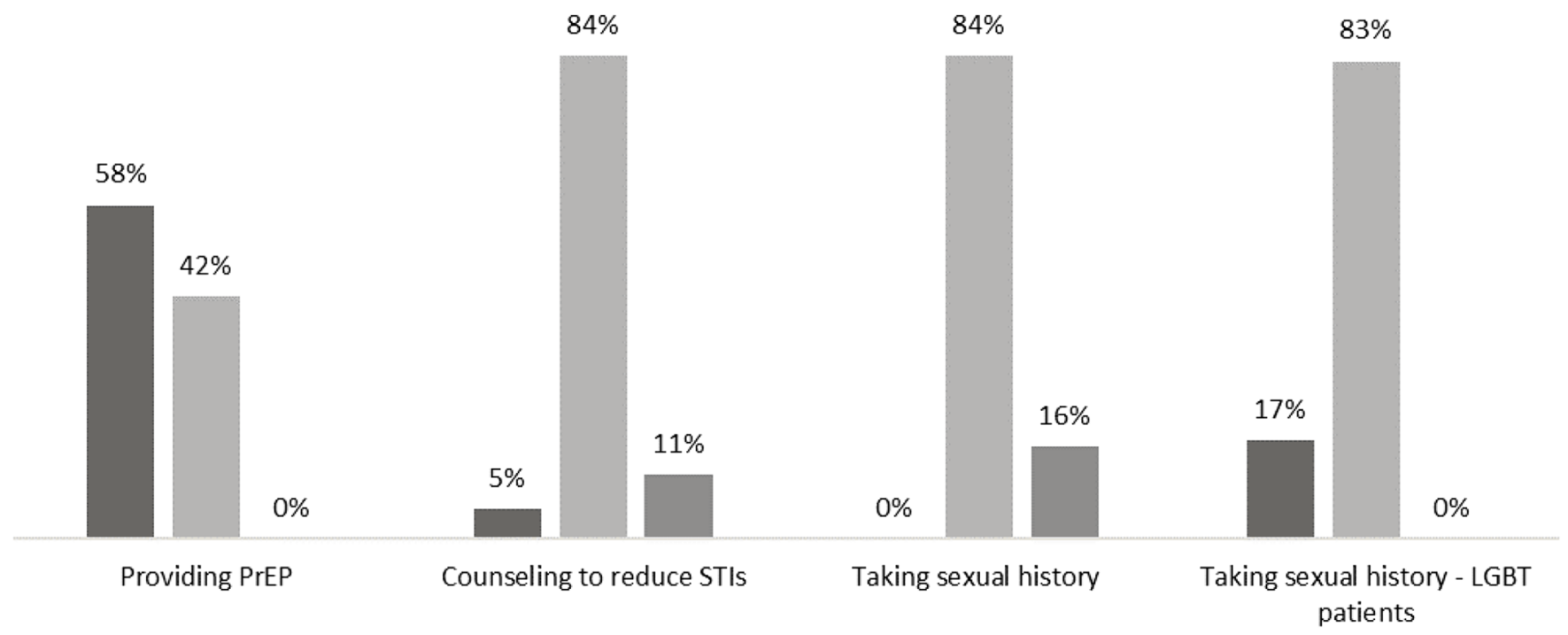

No training $\quad$ Some training or some but inadequate $\quad$ Extensive training

Figure 1 Prior training in HIV prevention curriculum content. 
Three interviewees noted the helpfulness of the case examples. One interviewee said:

"It was helpful to go through what seemed like real-life case examples and think through them systematically. [It was helpful to be able to do] practice cases in a safe environment."

\section{Clinical Experience}

All nine interviewees reported the clinical portion of the course was relevant and engaging. They noted the clinical experiences contributed to their competence by increasing their confidence and comfort to have sensitive conversations with patients. One resident explained:

"I think being able to discuss openly with patients some of the issues pertaining to a sensitive sexual history or sexually transmitted infections in an environment that was supportive, non-judgmental [by] asking the questions of the patient, I think that was really helpful in letting me become more comfortable with all the topics included."

Seven interviewees noted the helpfulness of the feedback they received during their clinical experience.

"Having somebody watch my interactions, especially surrounding the sexual history taking and talking about the options for contraception ... [was] helpful ... because right after the experience [s/he] gave me immediate feedback and I work best with that."

Interviewees reported the challenges with the clinical portion of the course were related to scheduling a sufficient number of patients. As a result, patient interactions were sometimes limited.

"I was only scheduled for one afternoon clinic, and I only saw one PrEP patient. It was relevant, but it was not the best. I think it would have been nice to have a full day or even two full afternoons where all I saw was PrEP patients.”

\section{Level 2: New Learning}

\section{Interview Results}

Eight of nine interviewees reported they learned most from the course content related to PrEP. Seven interviewees reported increased confidence and comfort in managing patients' sexual health concerns and discussing sexual practices, at least to a moderate extent.

"I think just feeling more comfortable in taking a detailed sexual history with patients, especially those that are at concern for some sort of an infection that we were not obviously finding."

Five interviewees reported improved attitudes about working with LGBTQ patients attributed to their new awareness and increased comfort level. One interviewee described the effect:

"Realizing that it is a complicated and complex thing. Even labeling someone as transgender, gay, or bisexual, it is all sort of the spectrum. It is hard to attach a specific label to someone. Each person is his or her own individual. That part was really brought to light."

Interviewees noted specific challenges related to working with the LGBTQ population that included patient reluctance to seek care because of fear of rejection and complex social, economic, and emotional factors. Another challenge to providing quality medical care noted was the complexity of various hormonal and pharmaceutical treatments.

\section{Survey Results}

Survey respondents $(n=19)$ as a group reported increases from pre- to post-survey in their comfort levels on all seven HIV Prevention topic areas, which were statistically significant $(p<0.05)$ (Table 2, Fig. 2). Consistent with interview results, the two areas of greatest increase were related to initiating discussions on PrEP and on safe sexual practices with LGBTQ patients $(p<0.0001)$. As evident in Figure 3, survey respondents rated their comfort levels as moderately high on pre-surveys (2.5-3.7 on a 5-point scale); yet, as a group, they reported increased levels on post-surveys in all areas. Only $10.5 \%$ were comfortable discussing PrEP pre-intervention, increasing to $84 \%$ post-intervention (Table 2). Notably, $68 \%$ of residents were "comfortable" or "very comfortable" with discussing safe sexual practices, yet only $26 \%$ felt comfortable with the same skill with LGBTQ patients. There were also lower comfort levels reported pre-survey in sexual history taking for LGBTQ patients, at $57 \%$.

In addition, a Spearman's correlation analysis found that questions 1-7 were strongly correlated with one another; thus, comfort level in taking a sexual history was correlated with ability to manage sexual health concerns (data not shown). The participants strongly valued the importance of understanding the patient's sexual health before and after the curriculum (Table 2). Preferred method of learning (Table 3) demonstrated a pre-post-trend towards interactive modules including online modules, standardized patients, and patient panels, but this did not reach statistical significance. The online modules were evaluated with separate post-survey questions (see online Appendix B), results noted in text boxes 1 and 2 
Text Box 1. Post-survey results on online modules: related to clinical experience

- $100 \%$ of respondents agreed that cases were the appropriate level of difficulty.

- $100 \%$ agreed they were actively engaged in revising their initial image of the patient's problem.

- $91 \%$ agreed they received feedback that was helpful to enhance their diagnostic reasoning.

Text Box 2. Post-survey results on online modules: related to indicators of behavior change

- $95 \%$ of respondents agreed they were better prepared to confirm a diagnosis in real-life patients with similar complaints.

- $91 \%$ agreed they were better prepared to care for real-life patients with similar complaints.

\section{Level 3: Behavior Change}

Six of nine interviewees reported they had applied what they learned after completing the course to patient care. One interviewee described:

"Definitely - at least two new patients that I have had, I have been able to actually apply [my learning]. For one patient on PrEP therapy ... I was able to talk to him about the benefits of it and his risk, which was really great to do."

All eight residents responding to the interview question concerning application of their new skills reported their organizations/institutions were supportive of the practices learned in the course. However, one interviewee qualified that, while individual faculty and residents were supportive, the general culture in their setting was less supportive.

Five interviewees indicated they planned to incorporate their new skills into future practice. Choice of career pathway/specialty area influenced how likely they were to see future application. One interviewee explained:

"I am about 80 percent sure that I want to go into primary care, so it is something that is definitely going to come in use in my future life in my practice."

\section{Level 4: Patient Results}

Five interviewees reported they had received feedback and had seen results that indicated their training would ultimately benefit the health of their patients. One resident described an example:

"My patient at [Clinic Name], being able to anticipate his needs from a sexual health standpoint and initiate that conversation about PrEP with him, and then eventually get him on PrEP. I think that was very good for his health, but also, I think it probably increased his confidence in me as a provider [who knew] to take that approach."

\section{Suggestions for Course Improvement}

Five interviewees suggested increasing contact with appropriate patients in the clinical portion of the course. Specifically, interviewees suggested course developers structure the clinical experiences to provide participants consistently with a variety of patients, including those receiving PrEP treatment.

Overall, interviewees reported they valued the course and would encourage other residents to take the elective, if appropriate to their career pathway.

"I think that it is a great course to take, especially for residents who are considering primary care because HIV specifically is becoming such a primary care problem nowadays. I think it is important for us to be able to manage it on our own."

"I would say do it because it allows you to get a more well-rounded experience in the taking a sexual history, communicating, and managing LGBT patients with sexual concerns because it is not the same as the nonLGBT community. You don't really get an in-depth experience like that elsewhere."

\section{DISCUSSION}

This innovative HIV prevention curriculum utilized a dedicated PrEP clinic setting and online virtual patient cases to teach a range of skills for inclusive sexual history taking, risk reduction counseling, and provision of PrEP. The model of integrating online modules with specific types of patient encounters and direct observation is a learnercentered curriculum with an opportunity to observe several milestones in internal medicine. The focus on health disparities with exposure to LGBTQ patients was designed to optimize training future PCPs to care for populations vulnerable to HIV. Prior studies demonstrated that exposure to LGBTQ patients can improve trainees' comfort level ${ }^{52-55}$ and can reduce implicit and explicit biases. ${ }^{56}$ Our study also demonstrated statistically significant improvement in trainees' sexual health skills for LGBTQ patients postcourse. Additionally, our study fills a gap in the literature on implementation and evaluation of HIV prevention curricula for trainees.

Our results show that prior to the curriculum, residents were uncomfortable with sexual history taking and managing sexual health concerns, particularly with LGBTQ patients. After our brief intervention, all participants were comfortable discussing safe sexual practices and taking sexual histories, with the greatest improvement seen for LGBTQ patients. Through the interviews, trainees expressed 


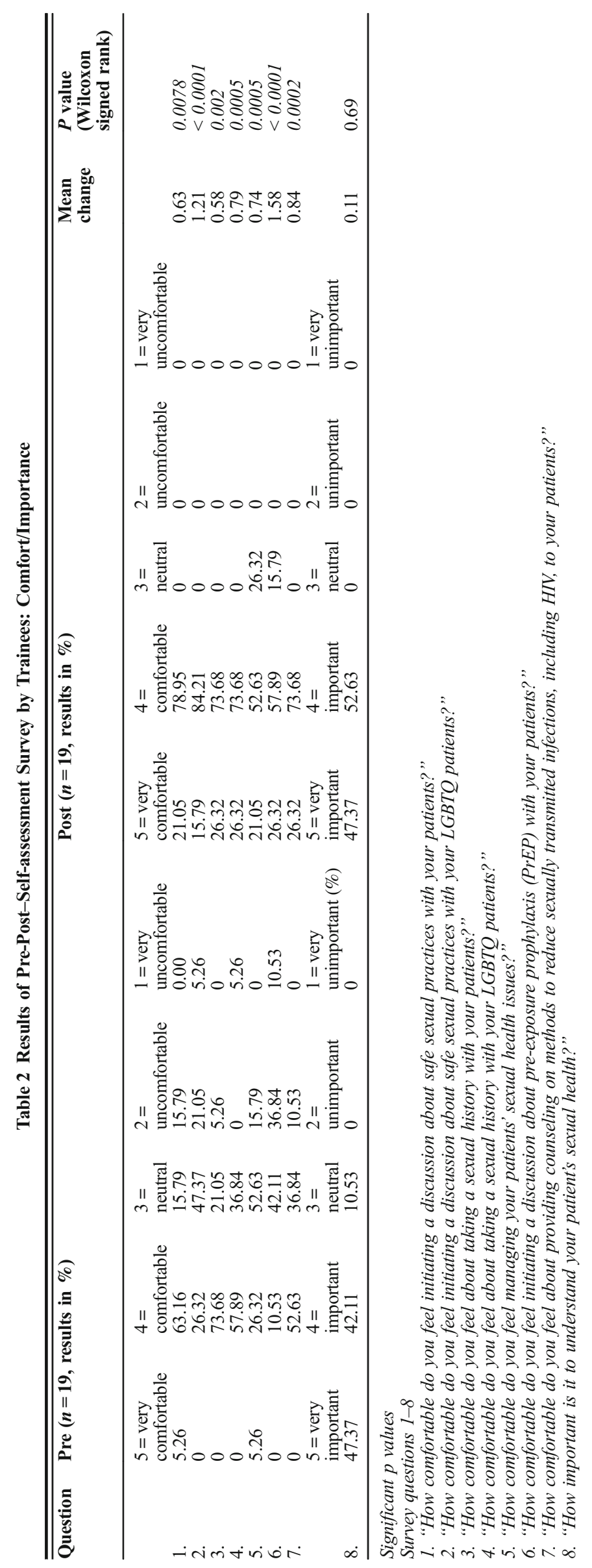


Table 3 Results of Pre-Post-Self-Assessment Surveys: Preferred Training Format

\begin{tabular}{llll}
\hline \hline $\begin{array}{l}\text { 13. What type of training } \\
\text { format would be helpful for } \\
\text { learning how to take a } \\
\text { sexual history? (select all) }\end{array}$ & $\begin{array}{l}\text { Pre } \\
(\%)\end{array}$ & $\begin{array}{l}\text { Post } \\
(\%)\end{array}$ & $\begin{array}{l}\boldsymbol{P} \text { value } \\
\text { (McNemar's } \\
\text { test) }\end{array}$ \\
\hline Didactics & 57.89 & 36.84 & 0.22 \\
Videotapes & 57.89 & 42.11 & 0.38 \\
Online module & 42.11 & 57.89 & 0.38 \\
Standardized patient & 26.32 & 31.58 & 1.00 \\
Patient panels & 68.42 & 78.95 & 0.50 \\
\hline
\end{tabular}

a benefit of exposure to LGBTQ patients that was missing in their training, with an understanding of health disparities and challenges in working with LGBTQ patients. They also noted that the online pre-clinic modules were a safe environment to practice, demonstrating this training model is an effective method for teaching sensitive conversations. While the respondents reported an increase in level of training post-survey, this failed to reach statistical significance. This may be due to a small sample size and/or limited exposure to patients, as described in the interview results.

While many medical schools have some sexual health and LGBTQ curriculum, our residents lack any formal training in sexual health, LGBTQ health, or HIV prevention, including PrEP. Our results on prior training showed most residents expressed gaps in their prior training in all areas addressed, which would have included a diverse number of medical school programs. Most sexual health and LGBTQ curricula are currently targeted at the medical school level; however, experts recommend training beyond. ${ }^{57}$ This curriculum's results support this suggestion that ongoing training for residents is needed in these areas to develop confidence necessary to manage sexual health issues, particularly with LGBTQ patients. Although a dedicated PrEP clinic with a large LGBTQ population provides valuable practice, it should be noted that the skills obtained are transferable to routine primary care for all patients.

Among the most interesting findings in our study were the lack of prior comfort and training in discussing PrEP, which improved after the participation in the course. This change was despite a brief experience on the rotation, an average of 4-8 h of combined modules and clinic experience. The interviews revealed that some participants only saw a handful of patients, demonstrating that even limited exposure to the content can increase confidence. Due to these findings, future directions for this elective will involve both increasing the number of sessions and continued efforts in recruitment and retention of patients. This is an implementation challenge as studies have shown PrEP retention in care is variable. ${ }^{58}$

Strengths of this study include a diverse group of residents with prior medical training at various medical school programs, and evidence of strong improvements across all skills analyzed, despite a small participant sample. In addition, pre- and post-survey response rates exceeded $60 \%$. The survey was modified from an existing survey in the literature, adding to the strength of its generalizability. Limitations of this study included that it was a single site study with a small number of participants. Specifically, our interviews did not reach thematic saturation due to a small number of participants, which may have limited the diversity of perspectives.

Future directions for the HIV prevention and PrEP curriculum will involve strengthening the PrEP Clinic's recruitment and retention in care efforts to improve trainees' patient exposure. Furthermore, expansion of the elective beyond internal medicine to other primary care specialties is being offered. Alternative options for expansion at other residency programs without a dedicated PrEP clinic could include a simulated patient program and use of the virtual patient cases. Finally, this model of integrating online subspecialty content-focused

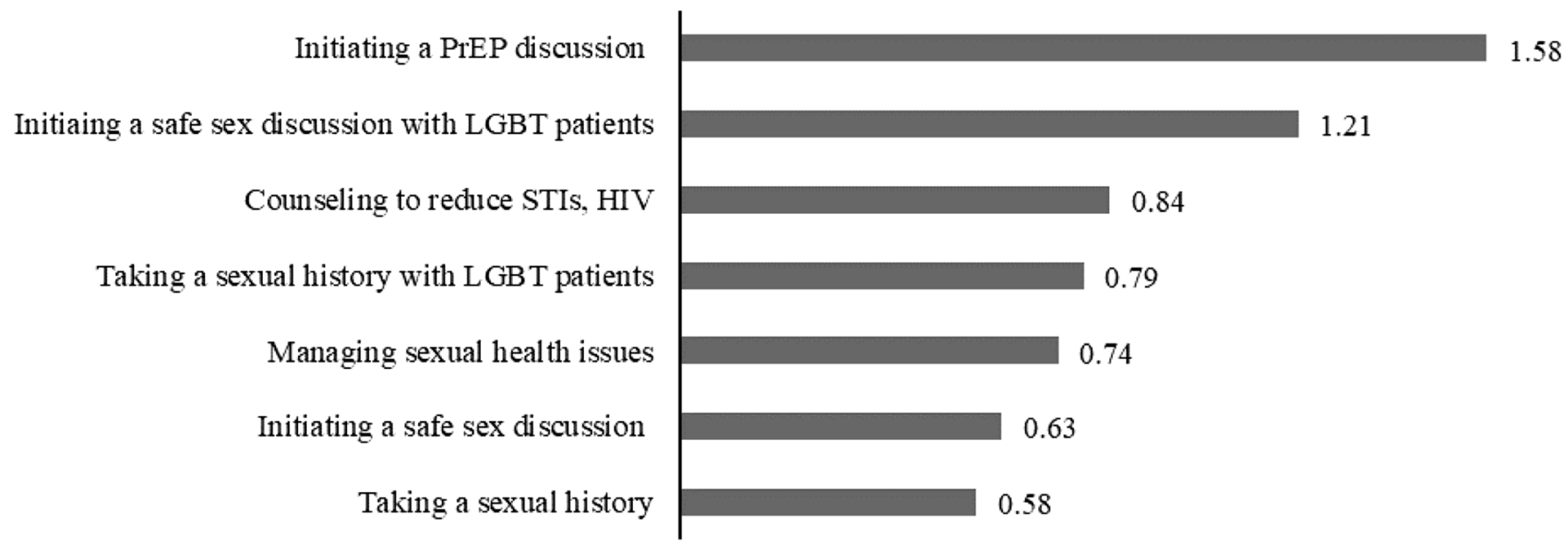

Figure 2 Mean change from pre- to post-survey (5-point scale)—sorted high to low. 
Taking a sexual history

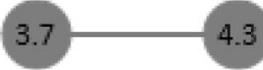

Taking a sexual history with LGBT patient

Initiating a safe sex discussion

Initiating a safe sex discussion

with LGBT patient

3.0

4.2

Initiating a PrEP discussion

2.5

Managing sexual health issues

Figure 3 Pre- and post-mean scores (5-point scale)—sorted high to low by post-score.

modules with patient encounters can be incorporated into other types of subspecialty learning as a "Just in Timing Teaching" type of curriculum.

Grants: Program for the Academic Clinician Educator, PACE, Department of Internal Medicine, University of Colorado Denver, Anschutz Medical Campus. Teaching Scholars Program, Academy of Medical Educators: biostatistical support.

Corresponding Author: Katherine Frasca, MD; Division of Infectious Diseases, University of Colorado, Aurora, CO, USA (e-mail: katherine. frasca@ucdenver.edu).

Contributors Victoria Hayes, M.D.: permission to use and adapt the survey for this study; Cindy Firnhaber, M.D., and Donna McGregor, N.P.: co-faculty facilitators in the PrEP Clinic; Yomi Obafemi: preventative medicine resident, review of curriculum; Janet Corral, Teaching Scholars Program: mentorship and access to SparkWorks software including post-online module survey questions; Rita Lee, M.D.: review of the curriculum.

\section{Compliance with Ethical Standards:}

Conflict of Interest: Nancy Madinger: NIH grant that has a for-profit company collaboration (Accelerate Diagnostics), NIH 1 RO1 AI11699301. Jose Castillo-Mancilla: NIH/NIAID K23AI104315 and R21AI124859. All remaining authors declare that they do not have a conflict of interest.

\section{REFERENCES}

1. Smith DK, Van Handel M, Wolitski RJ, et al. Vital signs: estimated percentages and numbers of adults with indications for preexposure prophylaxis to prevent HIV acquisition-United States, 2015. [Reprint in J Miss State Med Assoc. 2015 Dec;56(12):364-71; PMID: 26975161]. MMWR Morb Mortal Wkly Rep.. 2015;64(46):1291-5.

2. Centers for Disease Control and Prevention: National Center for HIV/ AIDS, Viral Hepatitis, STD and TB Prevention. CDC press release: HIV prevention pill not reaching most Americans who could benefit especially people of color. https://www.cdc.gov/nchhstp/newsroom/ 2018/croi-2018-PrEP-press-release.html. 2018. Accessed January 18 th, 2019.

3. Centers for Disease Control and Prevention. Preexposure prophylaxis for the prevention of HIV infection in the United States - 2017 update. A clinical practice guideline. https://www.cdc.gov/hiv/pdf/risk/prep/cdchiv-prep-guidelines-2017.pdf. 2017. Accessed January 18th, 2019.

4. Baeten JM, Donnell D, Mugo NR, et al. Single-agent tenofovir versus combination emtricitabine plus tenofovir for pre-exposure prophylaxis for HIV-1 acquisition: an update of data from a randomised, double-blind, phase 3 trial. Lancet Infect Dis. 2014;14(11):1055-64.

5. Grant RM, Lama JR, Anderson PL, et al. Preexposure chemoprophylaxis for HIV prevention in men who have sex with men. N Engl J Med. 2010;363(27):2587-99.

6. Grant RM, Anderson PL, McMahan V, et al. Uptake of pre-exposure prophylaxis, sexual practices, and HIV incidence in men and transgender women who have sex with men: a cohort study. Lancet Infect Dis. 2014;14(9):820-9.

7. Thigpen MC, Kebaabetswe PM, Paxton LA, et al. Antiretroviral preexposure prophylaxis for heterosexual HIV transmission in Botswana. N Engl J Med. 2012;367(5):423-34.

8. Centers for Disease Control and Prevention. HIV surveillance report 2017 volume 29. https://www.cdc.gov/hiv/pdf/library/reports/surveillance/ cdc-hiv-surveillance-report-2017-vol-29.pdf. 2017. Accessed January 18 th 2019.

9. Hess KL, Hu X, Lansky A, Mermin J, Hall HI. Lifetime risk of a diagnosis of HIV infection in the United States. Ann Epidemiol. 2017;27(4):238-43.

10. Baral SD, Poteat T, Stromdahl S, Wirtz AL, Guadamuz TE, Beyrer C. Worldwide burden of HIV in transgender women: a systematic review and meta-analysis. Lancet Infect Dis. 2013;13(3):214-22.

11. Hoornenborg E, Krakower DS, Prins M, Mayer KH. Pre-exposure prophylaxis for MSM and transgender persons in early adopting countries. AIDS. 2017;31(16):2179-91. 
12. Calabrese SK, Krakower DS, Mayer KH. Integrating HIV preexposure prophylaxis (PrEP) into routine preventive health care to avoid exacerbating disparities. Am J Public Health. 2017;107(12):1883-9.

13. Bien-Gund C, Patel VV, Blackstock OJ, Felsen U. Prep prescribing in primary care centers in a large urban health care system in the Bronx, New York. J Gen Intern Med. 2017;32(2):S284.

14. Silapaswan A, Krakower D, Mayer KH. Pre-exposure prophylaxis: a narrative review of provider behavior and interventions to increase PrEP implementation in primary care. J Gen Intern Med. 2017;32(2):192-8.

15. Blackstock OJ, Moore BA, Berkenblit GV, et al. A cross-sectional online survey of HIV pre-exposure prophylaxis adoption among primary care physicians. J Gen Intern Med. 2017;32(1):62-70.

16. Maude R, Volpe G, Stone D. Knowledge, attitude and practice of preexposure prophylaxis (PrEP) against HIV infection of medical providers at an academic center. Open Forum Infect Dis. 2017;4(Suppl 1):S437.

17. Krakower D, Mayer KH. Engaging healthcare providers to implement HIV pre-exposure prophylaxis. Curr Opin HIV AIDS. 2012;7(6):593-9.

18. Kumar P, Tanaka K, Kobashi B, Sheu L. Provider comfort and patient access to prep in internal medicine. J Gen Intern Med. 2017;32(2):S292.

19. Blumenthal J, Jain S, Krakower D, et al. Knowledge is power! Increased provider knowledge scores regarding pre-exposure prophylaxis (PrEP) are associated with higher rates of PrEP prescription and future intent to prescribe PrEP. AIDS Behav. 2015;19(5):802-10.

20. Tripathi A, Ogbuanu C, Monger M, Gibson JJ, Duffus WA. Preexposure prophylaxis for HIV infection: healthcare providers' knowledge, perception, and willingness to adopt future implementation in the southern US. South Med J. 2012;105(4): 199-206.

21. Park C, Khedimi R, Zingman B, Tinsley J, Starrels JL. HIV prevention with PrEP/PEP and sexual health in medical residency: a novel curriculum. J Gen Intern Med. 2017;32(2):S679.

22. Tiberio PJ, Williams K, Barakat LA, Edelman EJ, Virata M, Ogbuagu O. Prepared: implementation of a pre-exposure prophylaxis (PrEP) program in a hospital-based HIV clinic. J Gen Intern Med. 2016;31(2):S904-S5.

23. Imp B, Allen E, Volk J, Bhowmick T. Medical students have limited awareness, knowledge, beliefs, and experiences of pre-exposure prophylaxis (PrEP) for HIV prevention. Open Forum Infect Dis.. 2017;4:S14-S5.

24. Martin J, Burke K, Boettcher J, Bhalerao N, Huhn G. Reluctance to prescribe pre-exposure prophylaxis (PrEP) among internal medicine residents (IMRs) training at a U.S. hospital with a large HIV-infected population. Open Forum Infect Dis. 2017;4:S449-S50.

25. Calabrese SK, Earnshaw VA, Krakower DS, et al. A closer look at racism and heterosexism in medical students' clinical decision-making related to HIV pre-exposure prophylaxis (PrEP): implications for PrEP education. AIDS Behav. 2018;22(4):1122-38.

26. Parish SJ, Clayton AH. Sexual medicine education: review and com mentary. J Sex Med. 2007;4(2):259-67; quiz 68.

27. Madan AK, Caruso BA, Lopes JE, Gracely EJ. Comparison of simulated patient and didactic methods of teaching HIV risk assessment to medical residents. Am J Prev Med.. 1998; 15(2):114-9.

28. Coverdale $\mathbf{J H}$, Balon R, Roberts LW. Teaching sexual history-taking: a systematic review of educational programs. Acad Med. 2011;86(12):1590-5.

29. Malhotra S, Khurshid A, Hendricks KA, Mann JR. Medical school sexual health curriculum and training in the United States. J Natl Med Assoc. 2008;100(9):1097-106.

30. Rosen R, Kountz D, Post-Zwicker T, Leiblum S, Wiegel M. Sexual communication skills in residency training: the Robert Wood Johnson model. J Sex Med. 2006;3(1):37-46.

31. Haist SA, Griffith IC, Hoellein AR, Talente G, Montgomery T, Wilson JF. Improving students' sexual history inquiry and HIV counseling with an interactive workshop using standardized patients. J Gen Intern Med. 2004; 19(5 Pt 2):549-53.

32. Ivanova DK, Jones EA, Clayton AH. Medical student attitudes, knowledge, and comfort level related to patients' sexual health. J Sex Med. 2016;13(6):S241.

33. Sack S, Drabant B, Perrin E. Communicating about sexuality: an initiative across the core clerkships. Acad Med. 2002;77(11):1159-60.

34. Bonvicini KA. LGBT healthcare disparities: what progress have we made? Patient Educ Couns. 2017;100(12):2357-61.

35. Gorfinkle N, Allen J, Woolway D, Aluri J, Stewart RW, McGuire MJ. Using group reflection to help medical students process experience in care of sexual and gender minorities. J Gen Intern Med. 2016;31(2):S853.

36. Greene RE, Gillespie C, Hanley $\mathbf{K}$, Adams J, Zabar S. Meeting the primary care needs of transgender patients: using an objective structured clinical exam case to assess resident physicians' ability to provide primary care to transgender patients. J Gen Intern Med. 2015;30:S209.
37. Liang JJ, Gardner IH, Walker JA, Safer JD. Observed deficiences in medical student knowledge in transgender and intersex health. Endocr Pract. 2017;23(8):897-906.

38. Johnston CD, Shearer LS. Internal medicine resident attitudes, prior education, comfort, and knowledge regarding delivering comprehensive primary care to transgender patients. Transgender Health. 2017;2(1):91.

39. Park JA, Safer JD. Clinical exposure to transgender medicine improves students' preparedness above levels seen with didactic teaching alone: a key addition to the Boston University model for teaching transgender healthcare. Transgender Health. 2018;3(1):10-6.

40. Obedin-Maliver J, Goldsmith ES, Stewart L, White W, Tran E, Brenman S, et al. Lesbian, gay, bisexual, and transgender-related content in undergraduate medical education. JAMA. 2011;306(9):971-7.

41. Novak G, Patterson ET, Gavrin AD, Christian W. Just-in-time teaching: blending active learning with web technology. Upper Saddle River: Prentice Hall. 1999.

42. Centers for Disease Control and Prevention. Sexually transmitted diseases treatment guidelines, 2015. MMWR Morb Mortal Wkly Rep. 2015;64(3).

43. Centers for Disease Control and Prevention, U.S. Department of Health and Human Services. A guide to taking a sexual history. https://www. cdc.gov/std/treatment/SexualHistory.pdf;CDC Publication: 99-8445.

44. Nusbaum MR, Hamilton CD. The proactive sexual health history. Am Fam Physician. 2002;66(9): 1705-12.

45. Linda Creegan M, FNP. Brief, individual behavioral counseling for STD/ HIV risk reduction. National Network of STD/HIV Prevention Training Centers Curriculum Committee. http://nnptc.org/wp-content/uploads/ Behavioral-Counseling-Risk-Reduction-Curriculum-Module-2011.pdf. 2011. Accessed January 18th 2019.

46. The Joint Commission. Advancing effective communication, cultural competence, and patient- and familycentered care for the lesbian, gay, bisexual, and transgender (LGBT) community: a field guide. Oak Brook, IL, Oct. 2011. https://www.jointcommission.org/assets/1/18/ LGBTFieldGuide_WEB_LINKED_VER.pdf. Accessed January 18th, 2019.

47. National LGBT Health Education Center. A program of the Fenway Institute. Glossary of LGBT terms for healthcare teams. http://www. lgbthealtheducation.org/wp-content/uploads/LGBT-Glossary_ March2016.pdf . 2016. Accessed January 18th, 2019.

48. Gay and Lesbian Medical Association. Guidelines for the care of lesbian, gay, bisexual and transgender patients. http://glma.org/_data/n_0001/ resources/live/GLMA\%20guidelines\%202006\%20FINAL.pdf. 2006. Accessed January 18th, 2019.

49. Hayes V, Blondeau W, Bing-You RG. Assessment of medical student and resident/fellow knowledge, comfort, and training with sexual history taking in LGBTQ patients. Family Med. 2015;47(5):383-7.

50. Kirkpatrick DL, Kirkpatrick JD. Evaluating Training Programs: the Four Levels. 3rd ed. San Francisco: Berrett-Koehler Publication. 2006.

51. Kirkpatrick Partners L. The new world Kirkpatrick model https://www. kirkpatrickpartners.com/Our-Philosophy/The-New-World-KirkpatrickModel. 2009. Accessed January 18th, 2019.

52. Felder-Heim C, Kvach E, Powell K, Adams J. Preparing medical students for working with LGBTQ patients through the assessment of educational needs and the development of an LGBTQ health curriculum in the denver health longitudinal integrated clerkship (DH-LIC). J Gen Intern Med. 2017;32(2):S700.

53. Grosz AM, Gutierrez D, Lui AA, Chang JJ, Cole-Kelly K, Ng H. A student-led introduction to lesbian, gay, bisexual, and transgender health for first-year medical students. Fam Med. 2017;49(1):52-6.

54. Sanchez NF, Rabatin J, Sanchez JP, Hubbard S, Kalet A. Medical students' ability to care for lesbian, gay, bisexual, and transgendered patients. Fam Med. 2006;38(1):21-7.

55. Sekoni AO, Gale NK, Manga-Atangana B, Bhadhuri A, Jolly K. The effects of educational curricula and training on LGBT-specific health issues for healthcare students and professionals: a mixed-method systematic review. J Int AIDS Soc. 2017;20(1):21624.

56. Burke SE, Dovidio JF, Przedworski JM, et al. Do contact and empathy mitigate bias against gay and lesbian people among heterosexual firstyear medical students? A report from the Medical Student CHANGE Study. Acad Med. 2015;90(5):645-51.

57. Coleman E. Addendum to Summit on Medical School Education in Sexual Health: Report of an Expert Consultation. 2013.

58. Chan PA, Mena L, Patel R, et al. Retention in care outcomes for HIV preexposure prophylaxis implementation programmes among men who have sex with men in three US cities. J Int AIDS Soc. 2016;19(1):20903

Publisher's Note Springer Nature remains neutral with regard to jurisdictional claims in published maps and institutional affiliations. 